\title{
Geliştirilmiş Benzetilmiş Tavlama Algoritması Kullanılarak Minimum Fiyat, Minimum Ağırlık ve Maksimum Doğal Frekans Açısından Hibrit Grafit-Keten/Epoksi Tabakalı Kompozitlerin Optimum Tasarımı
}

\section{Optimum Design of Hybrid Graphite-Flax/Epoxy Laminated Composites for Minimum Cost, Minimum Weight and Maximum Frequency Using Modified Simulated Annealing Method}

\author{
Levent Aydın ${ }^{*} \oplus$, Melih Savran ${ }^{2} \oplus$ \\ 1 İzmir Katip Çelebi Üniversitesi Makine Mühendisliği Bölümü, İzmir, TÜRKiYE \\ 2 İzmir Katip Çelebi Üniversitesi Fen Bilimleri Enstitüsü, İzmir, TÜRKIYYE \\ Sorumlu Yazar / Corresponding Author*: leventaydinn@gmail.com
}

$\ddot{0} \mathbf{z}$

Otomotiv, havacıllk ve denizcilik endüstrilerindeki ekolojik yaklaşım, doğal liflerin (özellikle keten) yüksek doğal frekans, düşük maliyet ve ağırlık performansları nedeniyle cam elyaflara alternatif takviye malzemeleri olarak kullanılabileceğini göstermiștir. Bu bağlamda, bu çalıșma, keten lif kullanımının inter-ply hibrit kompozit yapılarda doğal frekans, maliyet ve ağırlık üzerindeki etkisini araştırmaktadır. Tabakalı kompozitlerin optimum açı dizilimlerinin tespiti Geliştirilmiş Benzetilmiş Tavlama Algoritması kullanılarak yapılmıştır. Mevcut çalışmada çok amaçlı optimizasyon yaklaşımı ile maksimum doğal frekansa sahip, hafif ve düşük maliyetli bir tasarım elde edebilmek için gerekli olan yüksek rijitliğe sahip düşük maliyetli tabakaların sayısı bulunmuștur. Bu çalıșma, doğal bir fiber olan keten'e ait doğal frekans-fiyat ve doğal frekans-ağırlık optimizasyon problemlerini tabakalı kompozit plakalar açısından inceleyen literatürdeki ilk çalışma olma özelliğini taşımaktadır. Sonuçlar, simetrik-balans hibrit grafit-keten/epoksi kompozit malzemenin spesifik rijitlik oranından taviz vermeden istenen frekans, fiyat ve ağırlı optimizasyonunu sağlayarak grafit/epoksi yerine kullanılmasının uygun olduğunu göstermiştir.

Anahtar Kelimeler: Hibrit tabakalı kompozit, doğal frekans optimizasyonu, fiyat ve ağırlık azaltımı, doğal fiber

\section{Abstract}

Ecological approach in automotive, aerospace and marine industries have stated that natural fibers (especially flax) can be used as alternative reinforcing materials to glass fibers because of their inherent good natural frequency, low cost and weight performances. In this regard, the present paper investigates the effect of the usage of flax fiber on fundamental frequency, cost and weight in interply hybrid composite structures. Stacking sequences design and optimization of laminated composites based on Modified Simulated Annealing algorithm is considered. The optimization 
problem is to find the number of high stiffness and less expensive laminates for maximum fundamental frequency-minimum cost and maximum fundamental frequency-minimum weight by multi objective optimization approach. The present study is the first to examine the frequency-cost and natural frequency-weight optimization problems of natural fiber reinforced laminated composites. The results show that the potential usage of symmetric-balance graphite-flax/epoxy hybrid composite material instead of graphite/epoxy is appropriate without sacrificing in stiffnessto-weight ratios.

Keywords: Hybrid laminated composite, fundametal frequency optimization, cost and weight reduction, natural fiber

\section{Giriș}

Kompozit malzemeler yüksek spesifik modül ve spesifik dayanım özellikleri sebebiyle pek çok sanayi uygulamasında yaygın bir şekilde kullanılmaktadır. Fiber takviyeli tabakalı kompozitler aynı zamanda doğası gereği fiber açı oryantasyonu ve dizilimi gibi parametrelerini değiștirebilmesine olanak sağlar. Bu avantajı tasarımcılara özgür ve geniș bir çalışma uzayı sunar. Dinamik mühendislik sistemlerinde, en önemli parametrelerden biri dış zorlama kuvvetleri sebebiyle ortaya çıkan rezonansla ilişkili doğal frekansdır. Bu sebeple, pek çok araştırmacı mühendislikte karşılaşılan doğal frekans optimizasyonu problemi ile ilgili çalıșmıșlardır. Tabakalı kompozit plakaların doğal frekans tasarım problemleri tek amaçlı optimizasyon yaklașımı kullanarak sürekli tasarım değișkenleri baz alınarak çözülmüștür. 1977 [1], 1987 [2] ve 1989 [3] yıllarında yapılmıș olan yayınlar bu tip çalışamaların ilk örneklerindendir. Aynı problemler ayrıca, cross-ply tabakalı yapılar için[4]; ve anizotropik tabakalı kompozitler için [5] tartışılmıştır. Benzer şekilde, bir diğer çalışmada doğal frekans kısıtları altında kompozit yapıların optimizasyonunu yapılmıştır [6]. Bu çalışmada her bir tabakanın kalınlığı tasarım değişkeni olarak alınmıştır. Başka bir çalışmada, ankastre mesnetli dikdörtgen tabakalı kompozit plakaların serbest titreșim problemi angle-ply ve cross-ply durumları için Ritz metodu kullanılarak çözülmüștür [7].

Farklı sınır koşulları dikkate alınarak, kompozit plakaların tabaka optimizasyonu maksimum doğal frekans açısından Genetik Algoritma (GA) stokastik yöntemiyle çözülmüştür [8]. Yukarıda bahsedilen dinamik gerekliliklere ek olarak, kompozit malzemelerden aynı zamanda düşük maliyet, hafiflik, düşük yoğunluk gibi bazı kritik özellekleri de sağlaması beklenebilir. $\mathrm{Bu}$ sebeple, birden fazla fiber yada matris malzemesi içeren fiber katkılı tabakalı kompozitlerin tasarımı için hibritleştirme prosesi temel olarak kullanılır. Hibritleștirme prosesine ait bir örnek, iç yüzeyinde ucuz ve düşük rijitliğe sahip bir malzeme ile dıș yüzeyinde pahalı ve yüksek rijitlikte bir malzeme kullanarak inter-ply hibrit bir tabakalı kompozit yapı tasarlamaktır. Bu tip çözüm önerilerinin avantajı, uygun yapısal rijitlik, hafiflik ve düșük maliyet kıstaslarını aynı anda karşılayabilecek konfügirasyonlara imkan tanımasıdır. Bununla birlikte, sistematik olarak optimum dizilimi elde etmek çok zordur. Yine de bu problem çok amaçlı ya da tek amaçlı optimizasyon yaklaşımları ile üstesinden gelinmiş durumdadır.

Örneğin, tek amaçlı yaklaşımı baz alarak; doğal frekans kısıtı altında antisimetrik, angle-ply hibrit tabakalı yapıların optimizasyonu problemi minimum fiyat açısından çözülmüştür [9]. Bir diğer çalışmada hibrit grafit-cam/epoksi inter-ply hibrit tabakalı yapılar için doğal frekans, frekans ayrımı ve fiyat faktörlerini dikkate alarak, optimum fiber oryantasyon açı dizilimi elde edilmiştir [10]. Benzer şekilde, çok amaçlı optimizasyon yaklașımı ile, maksimum doğal frekans ve minimum fiyat șartlarını eș zamanlı olarak sağlayan kompozit grafitcam/epoksi simetrik inter-ply hibrit tabakalı yapıların tasarım ve optimizasyonu başarıyla gerçekleştirilmiştir [11]. Bu alandaki ikinci bir önemli çalışma olarak, grafit-cam/epoksi interply hibrit tabakalı yapıların optimum açı dizilimi ve iç ve dış yüzeylerde kullanılacak olan malzemelere ait tabaka sayılarının belirlenmesi problemi verilebilir [12]. $\mathrm{Bu}$ çalışmada minimum ve maksimum yapılması istenen fiziksel büyüklükler minimum fiyat, maximum doğal frekans ve frekans ayırımıdır. Bir diğer çalışmada belirli frekans kısıtları altında minimum fiyat ve ağırlık optimizasyonu problemi çalışılmıştır [13].

Tabakalı kompozit malzemelere ait optimum tasarım problemleri, yüksek dereceden nonlineerlik ve karmaşık fonksiyonel yapılar içerdiğinden, geleneksel metotlar yerine stokastik yöntemlerle çözülmeye çalışılmıştır. Örneğin, maksimum doğal frekans ve sabit 
rijitlik durumlarını göz önüne alarak, basit mesnetli ve ankastre mesnetli simetrik ve simetrik olmayan tabakalı kompozit plakaların optimum fiber açı dizilimlerini bulabilmek için stokastik bir metot olan Diferansiyel Gelişim Algoritması (Differential Evolution) kullanılmıștır [14]. Benzer șekilde Genetik Algoritma (Genetic Algorithm) [15], Benzetilmiş Tavlama (Simulated Annealing) [16] ve Karınca Kolonisi (Ant Colony) [11] optimizasyon algoritmaları da kullanılarak çok amaçlı yaklaşım formülasyonları baz alınarak tabakalı kompozit plakalar doğal frekans maksimizasyonu ve fiyat minimizasyonu açısından değerlendirilmişlerdir. Seçkinci Karınca Koloni (Elitist Ant System) [17] ve Genetik Algoritma [13] minimum fiyat ve ağırlık şartlarını sağlayan cam/epoksi ve karbon/epoksi tabaka sayılarını optimize etmek için stokastik arama metotları olarak çalıștırılmıștır. Bunlara ek olarak, bazı araştırmacılar, optimizasyon problemleri için Genetik Algoritma, Genelleștirilmiş Örüntü Arama (Generalized Pattern Search), ve Benzetilmiş Tavlama (BT) gibi farklı stokastik optimizasyon yöntemlerini birbirleriyle performans açısından karşılaștırmışlar; bu karşılaştırmaları yaparken tabakalı kompozitler [18], kafes sistemleri[19] ve yapisal elemanlar[20] gibi sistemlerin tasarımını örnek problem olarak seçmişlerdir.

Son 10-15 senelik dönemde otomotiv, havacılık, denizcilik ve yapı sektörleri gibi büyük ve önemli endüstriler yüksek dayanım, düşük maliyet hafiflik ve çevre dostu olma şartlarına haiz malzemeleri geliștirme arayıșına girmişlerdir [21]. Bir doğal fiber olarak, "keten" yüksek spesifik dayanım ve düșük yoğunluk özelliklerine sahiptir. $\mathrm{Bu}$ sebeple tabakalı kompozit sistemlerde cam fibere alternatif olarak kullanılmaya bașlamıștır. Keten'in titreșim sönümleme [21], fiyat-performans indeksi [22], yanmazlık ve yüksek yapışma kabiliyeti gerektiren uygulamalar[23, 24] ve darbe davranışı [25] açısından geleneksel cam fibere alternatif olarak kullanılması ile ilgili detaylı değerlendirmeler ilgili referanslarda mevcuttur. Keten fiberin mekanik özellikleri birçok araștırmacı tarafından araștırılmıș olmakla birlikte, sönümleme ve titreșim yetenekleri ile ilgili çok az çalıșma bulunmaktadır. Bu bağlamda, bu çalıșma, doğal frekans, maliyet ve ağırlık açısından hibrit kompozit yapılarda, alternatif olarak keten kullanımını optimizasyon sistematiği altında gösterme çabasıdır. Bununla birlikte, doğal elyaf takviyeli lamine kompozitlerin frekans-maliyet ve doğal frekans-ağırlı optimizasyonu problemlerini inceleyen ilk çalışmadır.

Mevcut çalışmada, simetrik ve balans yapıda, inter-ply hibrit grafit-keten/epoksi tabakalı kompozitin maksimum doğal frekans, hafiflik ve minimum maliyet içerecek şekilde optimum açı diziliminin stokastik bir optimizasyon yöntemi ile çözülmesi incelenmiştir. Tasarım adımında algoritma olarak standart BT metodunun ayrık ve tamsayılı çözüm uzayı içerisinden seçilmesine olanak sağlayacak modifiye edilmiş bir versiyonu kullanılmıștır. Fiber oryantasyon açıları, iç ve dış yüzeylere ait malzeme tabaka sayıları ve kalınlıkları optimizasyon problemine ait tasarım değişkenleri olarak belirlenmiştir.

\section{Materyal ve Metot}

Ele alınan tabakalı kompozit plaka basit mesnetli, özellikli ortotropik (specially orthotropic) ve $a$ boyunda, $b$ genişliğinde ve $h$ toplam kalınlığına sahip bir yapıdadır (Bkz. Șekil 1). Her bir tabakaya ait fiber açı oryantasyonları $\theta$ ile verilmektedir. Malzemenin homojen, tabakaların da birbirine eșit kalınlıkta olduğu varsayılmıștır [26].

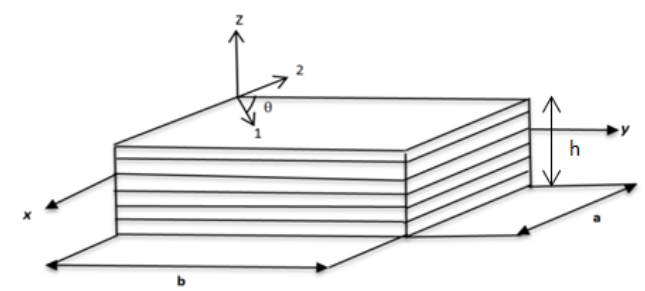

Şekil 1. Elyaf takviyeli tabakalı kompozit bir plaka

Hareket diferansiyel denklemleri simetrik tabakalı yapılar için Klasik Laminasyon Teorisi kullanılarak așağıdaki șekilde ifade edilebilir [26]:

$D_{11} \frac{\partial^{4} w}{\partial x^{4}}+4 D_{16} \frac{\partial^{4} w}{\partial x^{3} \partial y}+2\left(D_{12}+2 D_{66}\right) \frac{\partial^{4} w}{\partial x^{2} \partial y^{2}}+$

$4 D_{26} \frac{\partial^{4} w}{\partial x \partial y^{3}}+D_{22} \frac{\partial^{4} w}{\partial y^{4}}=\rho h \frac{\partial^{2} w}{\partial t^{2}}$

Eş. (1) de $w, h$ ve $t$ sırasıyla $z$ yönündeki deplasman, tabakalı yapıya ait toplam kalınlık ve zamanı ifade etmektedir. Kütlesel yoğunluk $\rho$ ve eğilme rijitlik matrisi $D_{i j}{ }^{\prime}$ ne ait elemanlar aşağıdaki gibi tanımlanabilir. 
$\rho=h^{-1} \int_{-h / 2}^{h / 2} \rho^{(k)} d z=\frac{1}{N} \sum_{k=1}^{N} \rho^{(k)}$

$D_{i j}=\frac{1}{3} \sum_{k=1}^{N} \int_{z_{k}}^{z_{k+1}} \overline{Q_{l \jmath}}(k) z^{2} d z$

burada $N$ toplam tabaka sayısını, $k$ kaçıncı tabaka olduğunu, $\bar{Q}_{i j}^{(k)}$ ise k. tabakaya ait dönüştürülmüş indirgenmiş rijitlik matrisini gösterir. Basit mesnetli plakaya ait sınır şartları matematiksel olarak

$$
\begin{aligned}
& x=0 d a w=0, y=0 d a w=0 \\
& x=0 d a M_{x}=0, y=0 d a M_{y}=0
\end{aligned}
$$

şeklinde ifade edilebilir. Burada moment ifadeleri aşağıdaki gibi tanımlanır:

$$
\left(M_{x}, M_{y}\right)=\int_{-h / 2}^{h / 2}\left(\sigma_{x}, \sigma_{y}\right) d z
$$

Eş. (5) te ortaya çıkan $\sigma_{x}, \sigma_{y}$ terimleri sırasıyla $x$ ve $y$ yönlerindeki normal gerilmeleri ifade eder. Bilindiği gibi tabakalı kompozit malzemeler eğer fiber açı dizilimlerinde sadece 0 ve 90 dereceyi içeriyorsa özellikli ortotropik yapılar olarak tanımlanır. Bununla birlikte simetrik özellikli bir ortotropik yapı için rijitlik matris elemanlarından $\mathrm{A}_{16}=\mathrm{A}_{26}=\mathrm{B}=\mathrm{D}_{16}=\mathrm{D}_{26}=0$ olduğu göz önüne alınmalıdır. Tabakalı kompozitlerde burkulma problemlerinde eğilme ve bükülme etkileşimine ait detaylı tartışma ve incelemeleri [27] referansında bulmak mümkündür. Bunlara ek olarak, tabakalı kompozitlerin özellikli ortotropik olmadığı durumlarda, terimlerinin sisteme olan etkileri eğer aşağıdaki şartlar sağlanırsa ihmal edilebilicek seviyede olur.

$\gamma \leq 0.2, \delta \leq 0.2$

burada

$$
\begin{aligned}
& \gamma=D_{16}\left(D_{11}^{3} D_{22}\right)^{-1 / 4} \\
& \delta=D_{26}\left(D_{11} D_{22}^{3}\right)^{-1 / 4}
\end{aligned}
$$

Burkulma ve serbest titreșim analizlerinin benzerliği göz önüne alındığında, aynı kısıtlar problemlerin sadeleștirilmeleri için kullanılabilir. Özellikli ortotropik tabakalı kompozit malzemeler ile ilgili yukarıdaki değerlendirmeler ışı̆̆ında, doğal frekans modları $(\mathrm{m}, \mathrm{n})$ için deplasman fonksiyonu $w$, Eş.
(1) de verilen kısmi diferansiyel eșitliğin 4 kenardan basit mesnetli bağlantı şartları altında çözümü olarak ikili seri açılımı formunda ifade edilebilir.

$w(x, y, t)=$

$\sum_{m=1}^{\infty} \sum_{n=1}^{\infty} A_{m n} \sin \frac{m \pi x}{a} \sin \frac{n \pi y}{b} e^{i \omega_{m n} t}$

burada $(\mathrm{m}, \mathrm{n})$ titreșim modlarına ait doğal frekans parametresini tanımlar.

$$
\begin{gathered}
\omega_{m n}^{2}=\frac{\pi^{4}}{\rho h}\left[D_{11}\left(\frac{m}{a}\right)^{4}+2\left(D_{12}+\right.\right. \\
\left.\left.2 D_{66}\right)\left(\frac{m}{a}\right)^{2}\left(\frac{n}{b}\right)^{2}+D_{22}\left(\frac{n}{b}\right)^{4}\right]
\end{gathered}
$$

Bilindiği gibi, m ve n' ye ait farklı değerler farklı mod şekillerine karşıllı gelmekte olup, doğal frekans $m=n=1$ durumunda elde edilebilir.

\subsection{Optimizasyon}

Mühendislik tasarım ve optimizasyonu problemleri birçok farklı optimizasyon algoritmaları ile çözülebilir. Bu algoritmalar geleneksel ve geleneksel olmayan yöntemler olarak sinıflandırılabilirler. Kisitlı Varyasyon, Analiz Yöntemi ve Lagrange Çarpanları vb. metotlar geleneksel optimizasyon yöntemleri olarak bilinir ve analitik olarak sadece sürekli ve türevlenebilir fonksiyonları içeren optimizasyon problemlerinin çözümünde kullanılabilirler. Bununla birlikte, kompozit malzemelerin mekaniğini içeren optimizasyon problemlerinin karmașıklığı, özellikle elde edilen amaç fonksiyonlarının eş zamanlı ayrık ve sürekli yapısı ile elde edilecek çözümlerin tamsayılı programlama içerme zorunluluğu araștırmacıları stokastik yöntemlerin ağırlıkta olduğu yeni ve alternatif algoritmaları kullanma ve geliştirmelerini zorunlu kılmıştır [28].

\subsubsection{Geliștirilmiș benzetilmiș tavlama algoritması}

Geleneksel "BT" algoritması, metallerin tavlama işlemini analoji yoluyla taklit eder. Genel olarak yapının yerel bir minimumdan uzaklașmasına ve global optimum noktayı araştırmasina izin verir. İlk adımda, her iterasyonda yeni bir nokta rastgele oluşturulur. Yeni noktanın mevcut noktadan uzaklığı Boltzmann'ın olasılık dağılımına dayanır ve durma kriterleri karşılanırsa algoritma durur [29]. Dağılım, bir sistemin enerjisini “T” sicaklığındaki termal dengede gösterir. Bu dağılım aşağıdaki şekilde ifade edilebilir: 
$P(E)=e^{-E} /(k T)$

burada P(E), E enerji seviyesindeki olasılığı, k, Boltzmann' sabitini, T ise sicaklığı gösterir. Deterministik yaklaşımdam farklı olarak, bu algoritma kullanılarak karışık-tamsayılı, sürekli ve/veya ayrık tip optimizasyon problemlerini çözmek mümkündür. Algoritmanın çalışma mantığını daha iyi anlayıp takip edebilmek için bir akış șeması Șekil 2 de ayrıca verilmiștir.

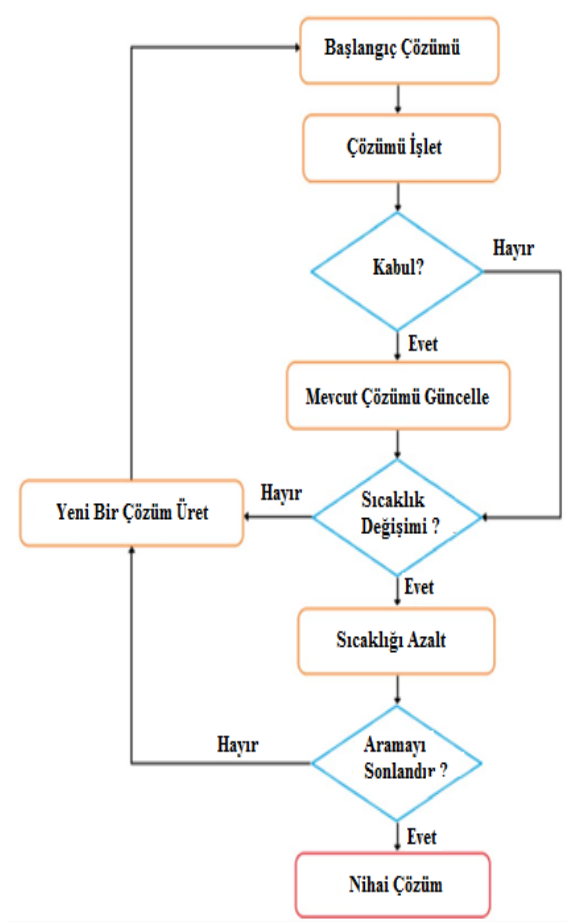

Şekil 2. Benzetilmiş Tavlama algoritması akıș şeması [29]

$\mathrm{Bu}$ çalışmada kullanılan GBT algoritması geleneksel olan BT algoritmasından biraz farklılık göstermektedir. Mathematica programı tabanında gerçekleştirilen çözümlemelerde "PostProcess" ve "PenaltyFunction" eklentileri algoritmaya global optimumu bulmada geleneksel halden çok daha güçlü bir süreç imkanı vermektedir. Bunun sebebi "PostProcess" eklentisi ile yerel minimum bulma algoritmalarını da algoritma hızlandırma amacıyla eș zamanlı hibrit uygulama imkanının olmasıdır. Bununla birlikte, geleneksel algoritmadan farklı olarak hibrit yapı kullanılması esnasinda "kısitlı" optimizasyon algoritmalarının da sürece dahil edilebilmesi "PenaltyFunction" komutu ile mümkün olmaktadır.

\subsection{Problem tanımı}

Bu çalışmada değișen en boy oranlarına (0.2-2) sahip hibrit olmayan (grafit/epoksi ve keten/epoksi) ile inter-ply hibrit (grafitketen/epoksi) tabakalı kompozit plakaların, Geliștirilmiş Benzetilmiş Tavlama Algoritma (GBT) kullanılarak optimum tasarımı problemleri incelenmiștir (Bkz. Şekil 3).

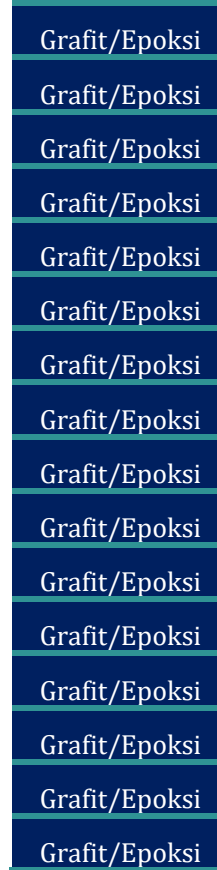

a.)

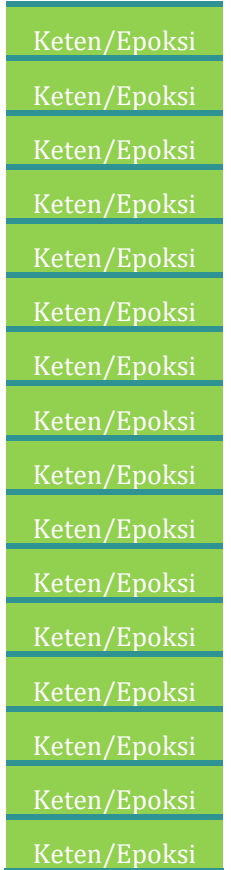

b.)

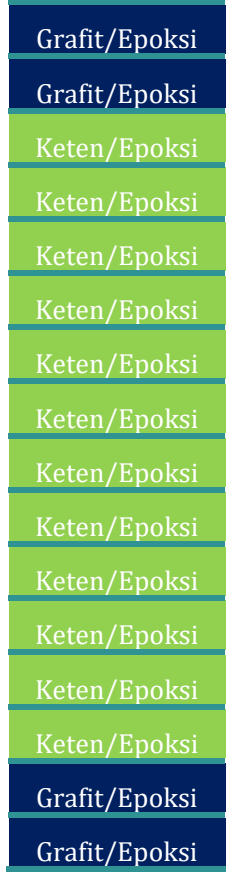

c.)
Şekil 3. Simetrik dizilime sahip a.) grafit/epoksi, b.) keten/epoksi c.)grafitketen/epoksi tabakalar

Tabakalar 16 adet üst üste simetrik ve balans yapıdan oluşmaktadır. Plaka genişliği $0.2 \mathrm{~m}$, her bir tabaka kalınlığ 0.000125 m'dir. Hibrit olmayan yapılar için doğal frekans ifadesi, tek amaçlı optimizasyon yaklaşımı kullanılarak maksimize edilmiştir. Hibrit yapılarda ise (i) maksimum doğal frekans ve minimum maliyet, (ii) maksimum doğal frekans ve minimum ağırlık çok amaçlı optimizasyon yaklaşımları ile eş zamanlı olarak çözüme gidilmiştir.

Malzeme olarak seçilen keten/epoksi ve grafit/epoksi ve cam/epoksi kompozitlerin mekanik özellikleri Tablo 1'de listelenmiştir. 
DEÜ FMD 21(63), 833-844, 2019

Tablo1.Cam/epoksi,grafit/epoksi, keten/epoksi malzemelerin mekanik özellikleri $[13,25]$

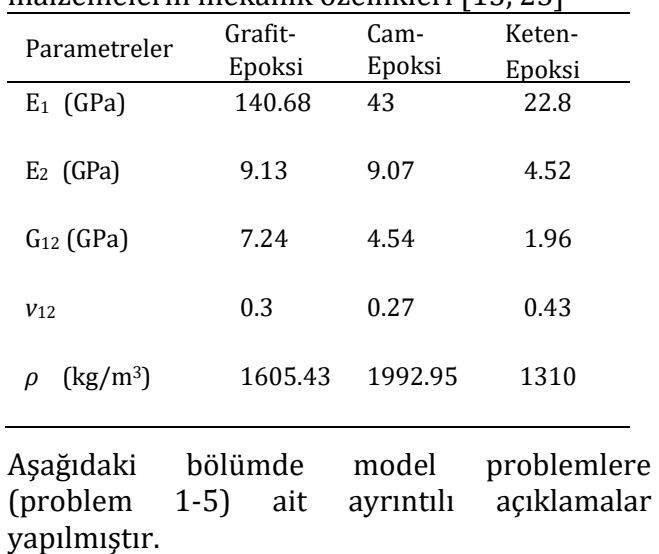

\section{Problem 1}

Hibrit yapılara ait hesaplanacak doğal frekans değerlerinin doğruluğunun ispatlanması için Grosset vd. [13] çalışmasındaki değişken tabaka sayılı simetrik-balans hibrit grafit-cam/epoksi kompozitin doğal frekans hesaplama sonuçları baz alınmıştır. Bu sayede, mevcut çalışma için yazılan klasik laminasyon teorisi tabanlı Mathematica kodu sonuçları ilgili referanstaki sonuçlarla karşılaştıralacaktır.

\section{Problem 2}

16 tabakal,, simetrik-balans, hibrit olmayan grafit/epoksi kompozit için doğal frekans maksimizasyonu problemi $15^{\circ}$ lik açı artırım ile GBT algoritması kullanılarak çözülecektir.

\section{Problem 3}

16 tabakall, simetrik-balans, hibrit olmayan keten/epoksi kompozit için doğal frekans maksimizasyonu problemi $15^{0^{\prime}}$ lik artırım ile GBT algoritması kullanılarak çözülecektir.

\section{Problem 4}

16 tabakalı, simetrik-balans, hibrit grafitketen/epoksi kompozit için doğal frekans, fiyat ve $F_{1}$ indeksi açısından optimum dizilim tasarım problemi $15^{\circ}$ lik artırım ile GBT algoritması kullanılarak çözülecektir. Optimizasyon problemi temel olarak, yüksek rijitliğe ve düşük maliyete sahip tabaka sayısını bulma üzerine yoğunlaşacak olup, doğal frekansı maksime edecek, fiyatı ise minimize edecek şekilde çok amaçlı optimizasyon yaklaşımı kullanılarak çözülecektir.

\section{Problem 5}

16 tabakalı, simetrik-balans, hibrit grafitketen/epoksi kompozit için doğal frekans, ağırlık ve $\mathrm{F}_{2}$ indeksi açısından optimum dizilim tasarım problemi $15^{0}$ lik artırım ile GBT algoritması kullanılarak çözülecektir $(b=0.2 \mathrm{~m}$, $\mathrm{t}=0.000125 \mathrm{~m})$. Optimizasyon problemi temel olarak, yüksek rijitliğe ve düşük ağırlığa sahip tabaka sayısını bulma üzerine yoğunlaşacak olup, doğal frekansı maksime edecek, ağırlığı ise minimize edecek şekilde çok amaçlı optimizasyon yaklaşımı kullanılarak çözülecektir.

Problem 4 ve 5'de "Penalty Function" formülasyonu kullanılarak çok amaçlı optimizasyon tanımlanacaktır. $\mathrm{Bu}$ bağlamda aşağıdaki ifadeler ( $F_{1}$ ve $F_{2}$ indeksleri) boyutsuz büyüklükler $f_{1}, f_{2}, f_{3}, g_{1}, g_{2}$, cinsinden kareleri toplamının lineer kombinasyonu olarak yazılabilirler [11]:

$$
\begin{aligned}
& F_{1}=k_{1} f_{1}^{2}+k_{2} f_{2}^{2}+c_{1} g_{1}^{2}+c_{2} g_{2}^{2} \\
& F_{2}=k_{1} f_{1}^{2}+k_{2} f_{3}^{2}+c_{1} g_{1}^{2}+c_{2} g_{2}^{2}
\end{aligned}
$$

burada $\mathrm{f}_{1}, \mathrm{f}_{2}, \mathrm{f}_{3}, \mathrm{~g}_{1}, \mathrm{~g}_{2}, \mathrm{k}_{1}, \mathrm{k}_{2}, \mathrm{c}_{1}$, and $\mathrm{c}_{2}$ aşağıdaki şekilde tanımlanırlar:

$$
\begin{aligned}
& f_{1}=\left(\frac{\omega_{\text {maksimum- }} \omega}{\omega_{\text {maksimum }}}\right) \\
& f_{2}=\left(\frac{\text { fiyat }}{\text { fiyat }_{\text {maksimum }}}\right) \\
& f_{3}=\frac{a \breve{g} \text { lrlık }}{\text { ăgrlı } k_{\text {maksimum }}} \\
& g_{1}=\delta-0.2 \\
& g_{2}=\gamma-0.2 \\
& k_{1}=k_{2}=c_{1}=c_{2}=1
\end{aligned}
$$

Eş. (12)-(14) de görülen " $\omega$ ", "fiyat" ve "ağırlık ifadeleri sırasiyla optimum frekans, fiyat ve ağırlık değerlerine takabül etmektedir. "Wmaksimum", "fiyatmaksimum" ve "ağırlıkmaksimum" parametreleri ise maksimum doğal frekans, maksimum fiyat ve maksimum ağırlık ifadeleri olup tüm tabakaların grafit/epoksi'den oluştuğu kabulüyle hesaplanır.

Ayrıca, $\omega$ maksimum için hesaplanan nümerik değerler, Problem 2'nin sonuçları baz alınarak elde edilir. $g_{1}$ ve $g_{2}$ "penalty" terimleri, diğer parametreler $k_{1}, k_{2}, c_{1}$, ve $c_{2}$ ise optimizasyon problemlerindeki amaç fonksiyonun ağırlık ölçüsüne göre ayarlanabilen katsayılardır. Bu çalışmada doğal frekans, fiyat ve ağırlık 
parametrelerinin tasarım açısından eșit önemde olduğu varsayıldığından $\mathrm{k}_{1}, \mathrm{k}_{2}, \mathrm{c}_{1}$ and $\mathrm{c}_{2}, 1$ olarak alınmștır.

$$
\begin{aligned}
& \text { fiyat }=a b \frac{h}{N}\left(\alpha_{0} \rho_{0} N_{0}+\rho_{i} N_{i}\right) \\
& \text { ăg } \iota r l ı k=a b \frac{h}{N}\left(\rho_{0} N_{0}+\rho_{i} N_{i}\right)
\end{aligned}
$$

Eş. (18) ve (19)' da a ve b plakanın uzunluk ve genişliğini, $\mathrm{N}_{0}$ grafit tabaka sayısını, $\mathrm{N}_{\mathrm{i}}$ keten tabaka sayısını, $\mathrm{N}$ toplam tabaka sayısını $\left(\mathrm{N}=\mathrm{N}_{0}\right.$ $+\mathrm{N}_{\mathrm{i}}$ ), $\rho_{0}$ diș (grafit/epoksi) tabakalara ait kütlesel yoğunluk, $\rho_{i}$ iç (keten/epoksi) tabakalara ait kütlesel yoğunluk değerlerini, $\alpha_{0}=20$ ise grafit/epoksi ile keten/epoksi karşılaştırmalı fiyat oran değerini gösterir.

\section{Bulgular}

Bu bölümde 16 tabakalı kompozit yapıların tek ve çok amaçlı optimizasyon yaklaşımı ile maksimum doğal frekans, minimum fiyat ve minimum ağırlık açısından optimum tasarım sonuçları verilmekedir. Tablo 2'de değişken tabakalı simetrik-balans hibrit grafitcam/epoksi kompozitin doğal frekans hesaplamaları ve literatürdeki sonuçlarla karşılaştırılması görülmektedir. Tablo incelendiğinde, mevcut çalışma için geliştirilen hesaplama süreci kullanılarak elde edilen sonuçlar ile Grosset vd. [13] çalışmasında verilen sonuçların aynı olduğu açıktır. $\mathrm{Bu}$ da optimizasyon problemlerinde (problem 2-5) amaç fonksiyonu ve/veya kısıt olarak kullanılan doğal frekans hesaplamaları için yazılan kodun uygun olduğunu teyit eder.

Tablo 2. Simetrik hibrit grafit-cam/epoksi kompozit için doğrulama çalışması $(\mathrm{a}=0.914 \mathrm{~m}$

\begin{tabular}{|c|c|c|}
\hline \multirow[b]{2}{*}{ Açı dizilimi } & \multicolumn{2}{|c|}{$\omega(h z)$} \\
\hline & $\begin{array}{c}\text { Grosset L. vd. } \\
{[13]}\end{array}$ & $\begin{array}{l}\text { Mevcut } \\
\text { calısma }\end{array}$ \\
\hline$\left[ \pm \underline{50} \underline{0}_{10} / \underline{0}\right]_{s}$ & 25.82 & 25.82 \\
\hline$[ \pm 50 / \pm \underline{50} 7]_{\mathrm{s}}$ & 25.10 & 25.10 \\
\hline$\left[ \pm 50_{2} / \pm \underline{50} 5\right]_{\mathrm{s}}$ & 25.88 & 25.88 \\
\hline$\left[ \pm 45_{2} / 90 / \pm \underline{50} 3 / \pm \underline{80}\right]_{\mathrm{s}}$ & 25.08 & 25.08 \\
\hline$\left[ \pm 50_{3} / 90 / \pm \underline{50} 2 / 0\right]_{\mathrm{s}}$ & 25.38 & 25.38 \\
\hline$\left[ \pm 50_{4} / \pm \underline{50} 2\right]_{\mathrm{s}}$ & 26.07 & 26.07 \\
\hline$\left[ \pm 50_{5} / 0\right]_{\mathrm{s}}$ & 25.14 & 25.14 \\
\hline
\end{tabular}
$\mathrm{b}=0.762 \mathrm{t}=0.000127 \mathrm{~m}$ )

(Altı çizili tabakalar: cam/epoksi)

16 tabakalı simetrik-balans grafit/epoksi ve keten/epoksi plakaların en/boy oranlarının doğal frekans maksimizasyonundaki etkisini görebilmek için, Tablo 3 ve 4' de GBT algoritması tabanlı optimum fiber açı dizilim tasarımı sonuçları listelenmiștir. Görüldüğü gibi, 0 ve 90 derece fiber oryantasyon açıları $\mathrm{a} / \mathrm{b}=0.2,0.4,0.6$ ve $1.8,2$ durumları için optimumdur. İkinci olarak, grafit/epoksi ve keten/epoksi kompozitlerin her ikisi için de en/boy oranı-fiber oryantasyon açısı ikilileri $0.8-30,1-45,1.2-45,1.4-60,1.6-75$ olarak hesaplanmıştır (Ayrica Tablo 3 ve 4 'e bakılabilir). Sonuçlara göre, maksimum doğal frekans değerleri grafit/epoksi için (219.663, $5347.6 \mathrm{rad} / \mathrm{sn}$ ) aralığında; keten/epoksi için (102.797, $2433.68 \mathrm{rad} / \mathrm{sn})$ aralığında elde edilmiştir.

Tablo 3. 16 tabakalı simetrik-balans hibrit olmayan grafit/epoksi kompozitin maksimum doğal frekans bakımından optimum açı dizilimi

\begin{tabular}{lll}
\hline $\mathrm{a} / \mathrm{b}$ & Açı dizilimi & $\omega(\mathrm{rad} / \mathrm{sn})$ \\
\hline 0.2 & {$\left[0_{8}\right]_{\mathrm{s}}$} & 5347.6 \\
0.4 & {$[08]_{\mathrm{s}}$} & 1357.13 \\
0.6 & {$[08]_{\mathrm{s}}$} & 619.034 \\
0.8 & {$\left[\mp 30 / \pm 30_{3}\right]_{\mathrm{s}}$} & 396.151 \\
1 & {$\left[\mp 45 / \pm 45_{3}\right]_{\mathrm{s}}$} & 310.642 \\
1.2 & {$\left[\mp 45 / \pm 45 / \mp 45_{2}\right]_{\mathrm{s}}$} & 261.528 \\
1.4 & {$[\mp 60 / \pm 60 / \mp 60 / \pm 60]_{\mathrm{s}}$} & 237.563 \\
1.6 & {$\left[\mp 75_{3} / \pm 75\right]_{\mathrm{s}}$} & 224.575 \\
1.8 & {$\left[90_{8}\right]_{\mathrm{s}}$} & 221.349 \\
2 & {$\left[90_{8}\right]_{\mathrm{s}}$} & 219.663 \\
\hline
\end{tabular}

Tablo 4. 16 tabakalı simetrik-balans hibrit olmayan keten/epoksi kompozitin maksimum doğal frekans bakımından optimum açı dizilimi

\begin{tabular}{lll}
\hline $\mathrm{a} / \mathrm{b}$ & Açı dizilimi & $\omega(\mathrm{rad} / \mathrm{sn})$ \\
\hline 0.2 & {$\left[0_{8}\right]_{\mathrm{s}}$} & 2433.68 \\
0.4 & {$\left[0_{8}\right]_{\mathrm{s}}$} & 627.489 \\
0.6 & {$\left[0_{8}\right]_{\mathrm{s}}$} & 294.015 \\
0.8 & {$\left[\mp 30_{3} / \pm 30\right]_{\mathrm{s}}$} & 190.549 \\
1 & {$\left[\mp 45_{2} / \pm 45_{2}\right]_{\mathrm{s}}$} & 149.186 \\
1.2 & {$\left[\mp 45_{3} / \pm 45\right]_{\mathrm{s}}$} & 125.795 \\
1.4 & {$\left[\mp 60_{4}\right]_{\mathrm{s}}$} & 113.803 \\
1.6 & {$\left[\mp 75_{3} / \pm 75\right]_{\mathrm{s}}$} & 106.991 \\
1.8 & {$\left[90_{8}\right]_{\mathrm{s}}$} & 104.406 \\
2 & {$\left[90_{8}\right]_{\mathrm{s}}$} & 102.797 \\
\hline
\end{tabular}

Şekil 4'te keten/epoksi ve grafit/epoksi kompozitlere ait maksimum doğal frekansların a/b'ye göre değişimi verilmiștir. Sonuçlara göre; 
DEÜ FMD 21(63), 833-844, 2019

keten/epoksi ve grafit /epoksi malzeme kullanıldığında doğal frekansın 0.2 ile 1 en/boy oranı aralığında önemli derecede düștüğ̈̈, 1 ile 2 en/boy oranı aralığındaki değişimden ise çok az etkilendiği görülür.

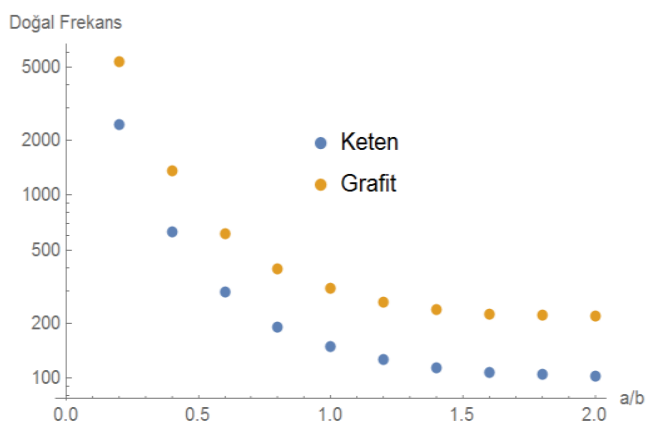

Şekil 4. Grafit ve keten epoksi kompozit için maksimum doğal frekansın plaka en-boy oranına bağlı değișimi

Tablo 5, 16 tabakalı simetrik-balans inter-ply hibrit grafit-keten/epoksi kompozitlerin doğa frekans, fiyat ve F1 indeksi açısından optimum fiber açı dizilimi tasarım sonuçlarını göstermektedir. Tablo incelendiğinde, grafitketen/epoksi'ye ait en yüksek frekans (4640.85 $\mathrm{rad} / \mathrm{sn}$ ) ile en düșük fiyat (0.1442) değerleri [06/干15]s şeklindeki dizilimle sağlanmıștır. Hibrit olmayan grafit/epoksi yerine hibrit grafit-keten/epoksi kullanımı fiyatta \%84 iyileșme sağlarken frekans açısından \%26 düşüş elde edilmiştir. Bu çalışmada frekans ve fiyat parameterlerinin her ikisinin de eşit önemde olduğu varsayıldığından hibrit yapı

kullanmanın çok daha avantajlı olduğu gösterilebilmiștir. $F_{1}$ indeksine ait tanımlamayı gözönüne alarak, optimum fiber açı oryantasyon dizilimi $\left[\mp 30 / \pm 30_{3}\right] \mathrm{s}$ olarak bulunmuştur. Başka bir deyişle, inter-ply hibrit kompozit yapılar kullanılarak yüksek doğal frekanslı ve düșük fiyatlı tabakalı kompozit malzemeleri herhangi bir rijitlik/ağırlık oran kaybı yaşanmadan tasarlamak olasıdır.

Tablo 6, 16 tabakalı simetrik-balans inter-ply hibrit grafit-keten/epoksi kompozitlerin doğal frekans, ağırlık ve $F_{2}$ indeksi açısından optimum fiber açı dizilimi tasarım sonuçlarını göstermektedir. Elde edilen sonuçlara göre; grafit-keten/epoksi'ye ait en yüksek frekans (4640.85 rad/sn) ile en düșük ağırlık (0.0221 kg) değerleri frekans-fiyat çalışmasında olduğu gibi yine $\left[0_{6} / \mp 15\right] \mathrm{s}$ şeklindeki dizilimle sağlanmıştır. Hibrit olmayan grafit/epoksi yerine hibrit grafit-keten/epoksi kullanımı ağırlıkta \% 13 civarında iyileșme sağlarken frekans açısından \%13 düşüş elde edilmiştir. Frekans ve ağırlığın tasarım açısından eşit önemde olduğu kabulüyle, ve $\mathrm{F}_{2}$ indeksine ait tanımlamayı da gözönüne alarak optimum fiber açı dizilim-en/boy oranı ikilileri $[\mp 302 / \pm 30 / \mp 30] s-0.8, \quad[\mp 452 / \pm 452] s-1.0$, $\left[\mp 45_{2} / \pm 45_{2}\right] \mathrm{s}-1.2$ olarak elde edilmiştir.

Bu çalışmada elde edilen bulguların literatüre katkısını arttırmak amacıyla, ek olarak bazı genelleştirme grafikleri hazırlanmıștır. Şekil 5 ve 6 ' de grafit/epoksi tabaka sayısı ve en/boy oranına bağlı olarak maksimum doğal frekans değişimleri 16 tabakalı simetrik-balans hibrit kompozit plakalar için gösterilmiştir. Görüldüğü gibi, plaka en/boy oranının >= 1.2 olduğu durumlarda doğal frekans değișimleri çok fazla olmamaktadır. Ayrıca, 8 grafit/epoksi tabaka kullanılarak doğal frekansı önemli ölçüde artırmak mümkündür.

\section{Tartışma ve Sonuç}

Bu çalıșmada simetrik-balans hibrit olmayan grafit/epoksi, keten/epoksi ile hibrit grafitketen/epoksi tabakalı kompozit tasarım ve optimizasyonu çalışmaları karşılaştırmalı olarak sunulmuştur. İki farklı çok amaçlı optimizasyon problemine cevap aranmiștır: (i) maksimum doğal frekans ve minimum fiyat, (ii) maksimum doğal frekans ve minimum ağırlık. Çözüm yöntemi olarak GBT Algoritması kullanılmış; 
DEÜ FMD 21(63), 833-844, 2019

Tablo 5. 16 tabakalı simetrik-balans hibrit grafit-keten/epoksi kompozitin frekans, fiyat ve $\mathrm{F}_{1}$ indeksi bakımından optimum açı dizilimi tasarımları

\begin{tabular}{cccccccc}
\hline $\mathrm{a} / \mathrm{b}$ & Açı dizilimi & $\begin{array}{c}\mathrm{N}_{\mathrm{o}} \\
\text { (grafit } \\
\text { sayısı })\end{array}$ & $\begin{array}{c}\omega \\
\text { (rad/sn) }\end{array}$ & Fiyat & $\begin{array}{c}\text { Frekans } \\
\text { düşüşü (\%) }\end{array}$ & $\begin{array}{c}\text { Fiyat } \\
\text { düşüşü } \\
(\%)\end{array}$ & $F_{1}$ \\
\hline 0.2 & {$\left[0_{6} / \mp 15\right]_{\mathrm{s}}$} & 4 & 4640.85 & 0.1442 & 13.22 & 71,93 & 0.0962 \\
0.4 & {$[08]_{\mathrm{s}}$} & 4 & 1180.05 & 0.2883 & 13.05 & 71,94 & 0.0958 \\
0.6 & {$[08]_{\mathrm{s}}$} & 4 & 539.94 & 0.4325 & 12.78 & 71,94 & 0.0951 \\
0.8 & {$\left[\mp 30 / \pm 30_{3}\right]_{\mathrm{s}}$} & 2 & 292.23 & 0.3302 & 26.23 & 83,93 & 0.0946 \\
1 & {$\left[\mp 45_{2} / \pm 45_{2}\right]_{\mathrm{s}}$} & 4 & 271.31 & 0.7208 & 12.66 & 71,94 & 0.0948 \\
1.2 & {$\left[\mp 45_{4}\right]_{\mathrm{s}}$} & 2 & 192.92 & 0.4953 & 26.23 & 83,93 & 0.0946 \\
1.4 & {$[\mp 60 / \pm 60 / \mp 60 / \pm 60]_{\mathrm{s}}$} & 4 & 207.42 & 1.0091 & 12.69 & 71,94 & 0.0948 \\
1.6 & {$\left[\mp 75 / \pm 75_{3}\right]_{\mathrm{s}}$} & 4 & 195.95 & 1.1532 & 12.75 & 71,94 & 0.0950 \\
1.8 & {$\left[90_{8}\right]_{\mathrm{s}}$} & 4 & 192.91 & 1.2974 & 12.85 & 71,94 & 0.0952 \\
2 & {$\left[90_{8}\right]_{\mathrm{s}}$} & 4 & 191.27 & 1.4416 & 12.93 & 71,94 & 0.0955 \\
\hline
\end{tabular}

Tablo 6. 16 tabakalı simetrik-balans hibrit grafit-keten/epoksi kompozitin frekans, ağırlık ve $F_{2}$ indeksi bakımından optimum açı dizilimi

\begin{tabular}{|c|c|c|c|c|c|c|c|}
\hline$a / b$ & Açı dizilimi & $\begin{array}{c}\mathrm{N}_{o} \\
\text { (grafit } \\
\text { sayısı) } \\
\end{array}$ & $\begin{array}{c}\omega \\
(\mathrm{rad} / \mathrm{sn})\end{array}$ & $\begin{array}{l}\text { Ağırlık } \\
\text { (kg) }\end{array}$ & $\begin{array}{c}\text { Frekans } \\
\text { düşüşü (\%) }\end{array}$ & $\begin{array}{c}\text { Ağırlık } \\
\text { düşüşü } \\
(\%)\end{array}$ & $F_{2}$ \\
\hline 0.2 & {$\left[0_{6} / \mp 15\right]_{s}$} & 4 & 4640.85 & 0.0221 & 13.22 & 13.96 & 0.7605 \\
\hline 0.4 & {$\left[0_{8}\right]_{\mathrm{s}}$} & 4 & 1180.05 & 0.0443 & 13.05 & 13.77 & 0.7600 \\
\hline 0.6 & {$\left[0_{8}\right]_{\mathrm{s}}$} & 4 & 539.94 & 0.0664 & 12.78 & 13.83 & 0.7593 \\
\hline 0.8 & {$[\mp 302 / \pm 30 / \mp 30]_{s}$} & 4 & 346.06 & 0.0885 & 12.64 & 13.87 & 0.7590 \\
\hline 1 & {$[\mp 452 / \pm 452]_{\mathrm{s}}$} & 4 & 271.31 & 0.1107 & 12.66 & 13.81 & 0.7590 \\
\hline 1.2 & {$\left[\mp 45_{2} / \pm 45_{2}\right]_{\mathrm{s}}$} & 4 & 228.46 & 0.1329 & 12.64 & 13.77 & 0.7590 \\
\hline 1.4 & {$[\mp 60 / \pm 60 / \mp 60 / \pm 60]_{s}$} & 4 & 207.42 & 0.1550 & 12.69 & 13.80 & 0.7591 \\
\hline 1.6 & {$\left[\mp 75 / \pm 75_{3}\right]_{\mathrm{s}}$} & 4 & 195.95 & 0.1771 & 12.75 & 13.82 & 0.7592 \\
\hline 1.8 & {$\left[90_{8}\right]_{\mathrm{s}}$} & 4 & 192.91 & 0.1993 & 12.85 & 13.79 & 0.7595 \\
\hline 2 & {$\left[90_{8}\right]_{\mathrm{s}}$} & 4 & 191.27 & 0.2214 & 12.93 & 13.81 & 0.7597 \\
\hline
\end{tabular}


DEÜ FMD 21(63), 833-844, 2019

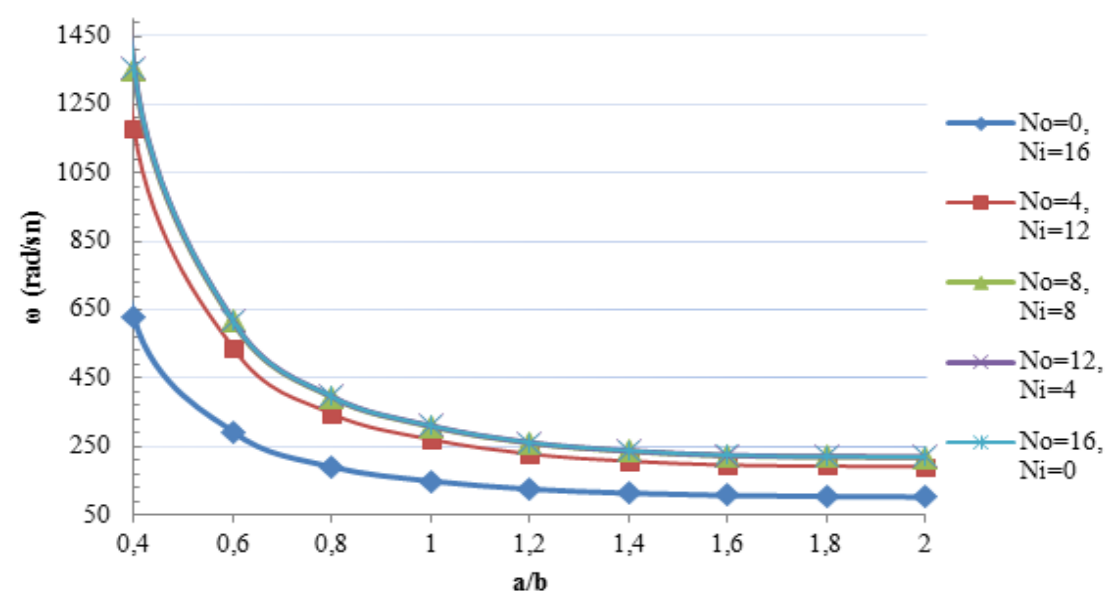

Şekil 5. 16 tabakalı grafit-keten/epoksi hibrit kompozitin doğal frekans değerlerinin en-boy oranına bağlı değişimi

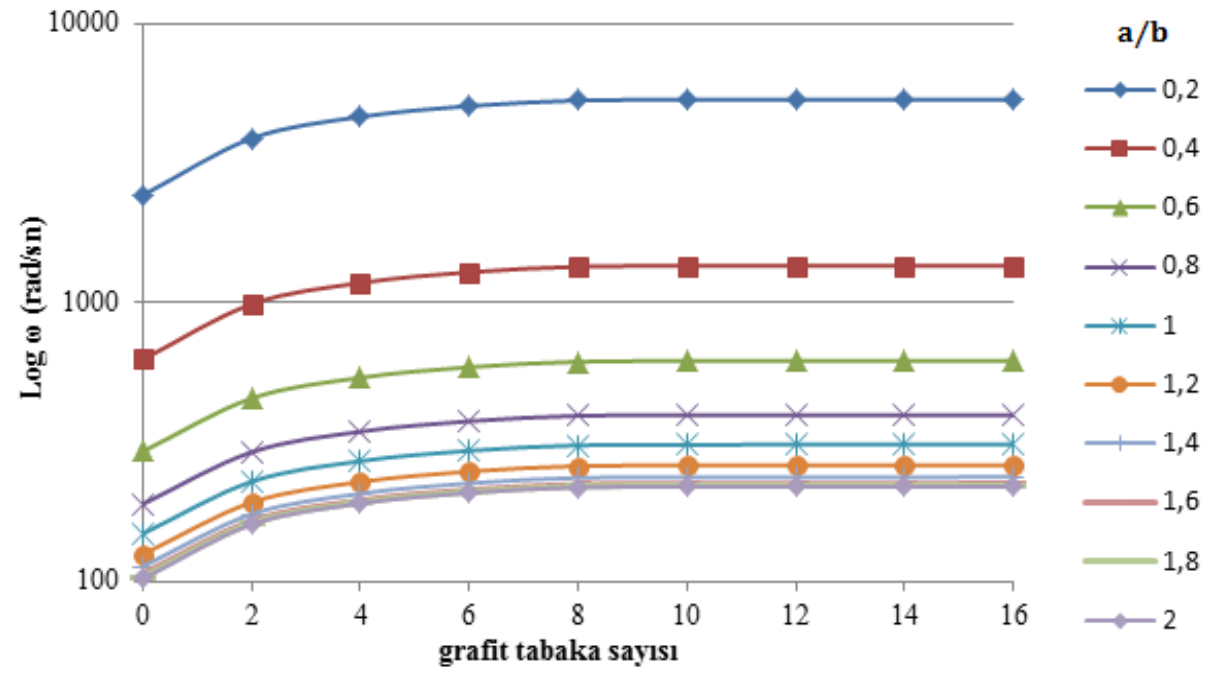

Şekil 6. 16 tabakalı grafit-keten/epoksi hibrit kompozitin doğal frekans değerlerinin grafit tabaka sayısına bağlı değişimi 


\section{DEÜ FMD 21(63), 833-844, 2019}

tasarım değișkenleri olarak fiber oryantasyon açıları, yüksek rijitlik ve fiyata sahip dış tabaka sayısı (No), düşük rijitlik ve fiyata sahip iç tabaka sayısı (Ni ) seçilmiştir. Sonuçlardan görülebileceği gibi, eğer doğal frekans tek başına optimizasyon problemlerinde amaç fonksiyonu olarak seçilirse, grafit/epoksi kompozit kullanımı keten/epoksi ve grafitketen/epoksi kompozit kullanımlarına göre daha avantajlı olmaktadır.

Bununla birlikte, fiyat ya da ağırlık amaç fonksiyonu olarak alınırsa, keten/epoksi uygun bir malzeme olarak düșünülebilir. Ancak, frekans ve fiyat açısından eş zamanlı bir performans beklendiği durumlarda dış tabakalarda grafit/epoksi iç tabakalarda ise keten/epoksi kullanılması uygundur. Burada not olarak eklemek gerekir ki hibrit grafitketen/epoksi tabakalı kompozitler ağırlık açısından fiyatta olduğu ölçüde avantajlı görünmemektedir.

Sonuç olarak așağıdaki genel değerlendirmeler yapılabilir:

(1) Hibrit kompozit yapıları kullanarak, rijitlik/ağırlık oranından taviz vermeden yüksek doğal frekansa ve düșük fiyata sahip yapılar tasarlamak mümkündür. $\mathrm{Bu}$ bağlamda, grafit/epoksi yerine hibrit grafit-keten/epoksi kullanım potansiyeli gösterilmiştir.

(2) Mevcut çalışma bir doğal fiber olan keten'e ait doğal frekans-fiyat ve doğal frekans-ağırlık optimizasyon problemlerini tabakalı kompozit plakalar açısından inceleyen ilk çalıșmadır.

(3) Elde edilen sonuçlar ışığında, doğal ve çevreci bir malzeme olan keten fiberin yüksek doğal frekans ve düşük fiyat ve ağırlık gerektiren uygulamalar için aday bir malzeme olarak önerilebileceği düşünülmektedir.

(4) Literatürde ancak bir kaç yüzeysel çalışma keten, kenevir, jut ve rami gibi doğal fiberlere ait mühendislik uygulamalarını teorik ve tasarım bazlı ele almıștır. Mevcut çalıșma bu anlamda bir boșluğu doldurabilecektir.

(5) Optimizasyon çalıșmalarının bir genellemesi olarak kritik en boy oranı 1.2, kritik grafit/epoksi sayısı ise 8 olarak belirlenmiștir.

\section{Kaynakça}

[1] Bert, C.W. 1977. Optimal design of a composite material plate to maximize its fundamental frequency, Journal of Sound and Vibration, Cilt. 50, (2), s. 229-237. DOI: 10.1016/0022460X(77)90357-1

[2] Reiss, R., Ramachandran, S. 1987. Maximum frequency design of symmetric angle-ply laminates, Composite Structures, Cilt. 4, s. 1476-1487. DOI: 10.1007/978-94-009-3455-9_37

[3] Grenestedt, J.L. 1989. Layup optimization and sensitivity analysis of the fundamental eigen frequency of composite plates, Composite Structures, Cilt. 12 (3), s. 193-209. DOI: 10.1016/0263-8223(89)90022-6

[4] Duffy, K.J, Adali, S. 1991. Maximum frequency design of pre-stressed symmetric, cross-ply laminates of hybrid construction,Advances in design automation, Cilt. 2, s. 477-484

[5] Adali, S. 1984. Design of shear-deformable anti symmetric angle-ply laminates to maximize the fundamental frequency and frequency separation, Composite Structures, Cilt. 2 (4), s. 349-369. DOI: 10.1016/0263-8223(84)90005-9

[6] Fukunaga, H., Sekine, H., Sato, M. 1994. Optimal design of symmetric laminated plates for fundamental frequency, Journal of Sound and Vibration, Cilt. 171 (2), s. 219-229. DOI: 10.1006/jsvi.1994.1115

[7] Narita, Y., Leissa, A. W. 1992. Frequencies and mode shapes of cantilevered laminated composite plates. Journal of Sound and Vibration, Cilt.154(1), s. 161172. DOI: $10.1016 / 0022-460 X(92) 90410-Y$

[8] Apalak, M.K., Yildirim, M., Ekici, R. 2008. Layer optimization for maximum fundamental frequency of laminated composite plates for different edge conditions, Composites Science and Technology, Cilt. 68, s. 537-550.

DOI: 10.1016/j.compscitech.2007.06.031

[9] Adali, S., Duffy, K. 1992. Minimum cost design of vibrating laminates by hybridization, Engineering Optimization, Cilt. 19(4), s. 255-267. DOI: $10.1080 / 03052159208941231$

[10] Adali, S., Verijenko, V.E. 2001. Optimum stacking sequence design of symmetric hybrid laminates undergoing free vibrations, Composite Structures, Cilt. 54(2-3), s. 131-138. DOI: 10.1016/S02638223(01)00080-0

[11] Abachizadeh, M., Tahani, M. 2009. An ant colony optimization approach to multi-objective optimal design of symmetric hybrid laminates for maximum fundamental frequency and minimum cost, Structural Multidisciplinary Optimization, Cilt. 37(4), s. 367-376. DOI: 10.1007/s00158-008-02356

[12] Lakshmi, K., Rao, A.R.M. 2015. Optimal design of laminate composite plates using dynamic hybrid adaptive harmony search algorithm, Journal of Reinforced Plastics Composites, Cilt. 34 (6), s. 493518. DOI: $10.1177 / 0731684415574228$

[13] Grosset, L., Venkataraman, S., Haftka, R. 2001. Genetic optimization of two-material composite laminates, In 16th ASC technical meeting. Blacksburg- Virginia.

[14] Roque, C. M. C., Martins, P. A. L. S. 2017. Maximization of fundamental frequency of layered 


\section{DEÜ FMD 21(63), 833-844, 2019}

composites using differential evolution optimization, Composite Structures, Cilt. 183, s. 7783. DOI: $10.1016 /$ j.compstruct.2017.01.037

[15] Tahani, M., Kolahan, F., Sarhadi, A. 2005. Genetic algorithm for multi-objective optimal design of sandwich composite laminates with minimum cost and maximum frequency, Proceedings of international conference on advances in materials, product design and manufacturing systems ICMPM, India, 741-748.

[16] Kolahan, F., Tahani, M., Sarhadi, A. 2005. Optimal design of sandwich composite laminates for minimum cost and maximum frequency using simulated annealing, Proceedings of Tehran international conference on manufacturing engineering TICME, Tahran-Iran, Aralık 12-15.

[17] Hemmatian, H., Fereidoon, A., Sadollah, A. Bahreininejad, A. 2013. Optimization of laminate stacking sequence for minimizing weight and cost using elitist ant system optimization, Advances in Engineering Software, Cilt. 57, s. 8-18. DOI: 10.1016/j.advengsoft.2012.11.005

[18] Aydin, L., Artem, H.S. 2011. Comparison of stochastic search optimization algorithms for the laminated composites under mechanical and hygrothermal loadings, Journal of Reinforced Plastics Composites, Cilt. 30 (14), s. 1197-1212. DOI: $10.1177 / 0731684411415138$

[19] Hasançebi, O., Carbas, S., Doğan, E., Erdal, F., Saka, M. 2010. Comparison of non-deterministic search techniques in the optimum design of real size steel frames, Computures and Structures, Cilt. 88 (17-18) s. $1033-1048$ DOI: $10.1016 /$ j.compstruc.2010.06.006

[20] Manoharan, S., Shanmuganathan, S. 1999. A comparison of search mechanisms for structural optimization, Computures and Structures, Cilt. 73 (1-5), s. $363-372$. DOI: 10.1016/S00457949(98)00287-9

[21] Prabhakaran, S., Krishnaraj, V., Senthil, K. M., Zitoune, R. 2014. Sound and vibration damping properties of flax fiber reinforced composites, Procedia Engineering, Cilt. 97, s. 573-81. DOI: 10.1016/j.proeng.2014.12.285

[22] Shah, D.U., Schubel, P.J., Clifford M.J. 2013. Can flax replace E-glass in structural composites? A small wind turbine blade case study, Composites Part B, Cilt. 52, s. 172-81. DOI: 10.1016/j.compositesb.2013.04.027

[23] Dittenber, D.B., Gangarao, H.V.S. 2012. Critical review of recent publications on use of natural composites in infrastructure, Composites Part A, Cilt. 43 (8), s. 1419-29.

DOI: 10.1016/j.compositesa.2011.11.019

[24] Yan, L., Chouw, N., Jayaraman, K. 2014. Flax fibre and its composites - A review, Composites Part B, Cilt. 56, s. 296-317.

DOI: $10.1016 /$ j.compositesb.2013.08.014

[25] Liang, S., Guillaumat, L., Gning, P. B. 2015. Impact behaviour of flax/epoxy composite plates, International Journal of Impact Engineering, Cilt. 80, s. 56-64.

DOI: $10.1016 /$ j.ijimpeng.2015.01.006

[26] Aydin, L., Artem, S., Oterkus, E., Gundogdu, O., Akbulut, H. 2017. Mechanics of fiber composites, Fiber Technology for Fiber-Reinforced Composites,
5-50. Seydibeyoglu, O., Mohanty, A., Misra, M. 2017. Fiber technology for fiber-reinforced composites Woodhead Publishing Series in Composites Science and Engineering, Cambridge, 325.

[27] Nemeth, M. 1986. Importance of anisotropy on buckling of compression-loaded symmetric composite plates, AIAA journal, Cilt. 24 (11), s. 1831-1835. DOI: $10.2514 / 3.9531$

[28] Deveci, H.A., Aydin, L., Artem, H.S. 2016. Buckling optimization of composite laminates using a hybrid algorithm under Puck failure criterion constraint, Journal of Reinforced Plastics Composites, Cilt. 35 (16), s. 1233-1247. DOI: $10.1177 / 0731684416646860$

[29] Ozturk, S., Aydin, L., Kucukdogan, N., Celik, E. 2018. Optimization of lapping processes of silicon wafer for photovoltaic applications, Solar Energy, Cilt. 164, s. 1-11. DOI: 10.1016/j.solener.2018.02.039

[30] Ozturk, S., Aydin, L., Celik, E. 2018. A comprehensive study on slicing processes optimization of silicon ingot for photovoltaic applications, Solar Energy, Cilt. 161, s. 109-124. DOI: 10.1016/j.solener.2017.12.040 